\title{
Healthy environment: a healthy investment for a healthier nation
}

\author{
Hemantha Herath \\ President, College of Community Physicians of Sri Lanka, 2017/18 \\ Anti-Malaria Campaign, Ministry of Health, Sri Lanka \\ Correspondence: hdbher@gmail.com
}

DOI: https://doi.org/10.4038/jccpsl.v24i3.8173

Received on: 26 June 2018

Accepted on: 28 June 2018

Famous Clay's Handbook of Environmental Health says, Albert Einstein has noted that environment is 'everything that's not me' (1). In physiology, this 'me' and 'not me' are identified as internal and external environment, respectively. According to Frumkin (2004), environment is all the external factors physical, nutritional, social, behavioural and others that act on the health of humans (2).

National Environmental Health Association of the United States of America (2017) defines environmental health as the science and practice of preventing human injury and illness; promoting wellbeing by identifying and evaluating the environmental sources and hazardous agents; and limiting exposures to hazardous physical, chemical and biological agents in air, water, soil, food and other environmental media/settings that may adversely affect human health (3). This definition contains two aspects namely environmental factors affecting health and practice of controlling such factors to improve human health.

The physical, social and biological environment of man is identified as an important determinant of health. Poor environmental sanitation, inadequate access to safe drinking water, excessive atmospheric pollution, etc. are important determinants in the physical environment affecting health (4). The socio-economic status, employment potential, positive employeremployee relationship, etc. are all important factors in man's social environment. The scope of environ- ment and its effects on human health is virtually limitless.

\section{Air pollution}

Sri Lanka is considered as a country with moderate air pollution (5). However, according to numerous sources, air quality problems in the country are increasing day by day (6). As reported by the Sri Lankan Scientist (2016), the amount of PM2.5 particles in the air in Colombo is 3.6 times the WHO safe level while that in Sri Lanka is 2.2 times the WHO safe level (7). These problems are due to the rapid rise in emissions of particulate matter and noxious gases from vehicular traffic, industrial emissions particularly from thermal power generation plants, rapid urbanization and trans-boundary transport of atmospheric contaminants from the Asia continent. The main source of ambient air pollution in Sri Lanka is vehicular emissions. According to the Ministry of Environment, it contributes to over $60 \%$ of the total emissions in Colombo. In this regard, increasing traffic volume, increasing traffic congestion, poor inspection and maintenance of vehicles, and poor quality of roads have been identified as major causes. Ministry of Transport (2017) reports an increasing number of vehicles in Sri Lanka, out of which the largest proportion is motor cycles and tricycles. Encouraging public transport is the solution applied by most countries to such increasing traffic volume and congestion (8). In Sri Lanka, widening of roads and construction of flyovers, etc. have been given priority over encouraging public transport. 
Further action on air pollution in Sri Lanka is definitely an investment for health.

\section{Water and sanitation}

According to the latest Demographic and Health Survey, one in ten households obtain drinking water from an unimproved source in the country as a whole while six out of ten households do so in the estate sector. This disparity needs prompt attention (9). Sri Lanka is moving towards a water crisis unless well prepared. Surface water in most parts of the country is increasingly polluted. As the level of pollution and dissolved substances in surface water is varying, such water is not allowed to be used for the bottling of drinking water. Shallow ground water in highly urbanized areas is also polluted and not suitable for standard use.

\section{Chemicals}

Exposure to chemicals can occur through the air, water, food and skin. Effects of chemicals may be immediate, acute as well as chronic, resulting from acute to long-term exposures. Chronic low-level exposure to various chemicals may result in a number of adverse health outcomes, including damage to the nervous and immune systems, impairment of reproductive function and development, cancer and organ-specific damage. As such, sound management of chemicals, particularly heavy metals, pesticides and persistent organic pollutants is a prerequisite for the protection of health.

Social and economic development in Sri Lanka has led to an exponential increase of chemical use by the people. In this regard, children and low income workers appear to be more at risk. The WHO emphasizes that the initial focus for action should be placed on the so-called 'intellectual robbers' namely lead, mercury and polychlorinated biphenyl as well as pesticides (10). Many activities are being implemented in Sri Lanka to address the issues related to chemicals.

\section{Radiation}

Radiation, both ionizing and non-ionizing has always been a natural part of our environment. Radiation and radioactive substances have many beneficial applications, ranging from power generation to uses in medicine, industry, consumer products and agriculture. As a result, the exposure to both types of radiation has been increasing over the past decades. Effects of ionizing radiation are well-documented and the need for protective measures is wellaccepted. However, regulation of radiation protection, especially in the light of expanded and widespread use of ionizing radiation beyond the traditional use is now becoming a challenge. In this regard, radiation risks to workers, the public and the environment that may arise from these applications need to be assessed and if necessary, controlled. Further, activities such as the medical uses of radiation, operation of nuclear installations, production, transport and use of radioactive material and management of radioactive waste must be subject to standards of safety.

There has been a dramatic expansion of exposure to non-ionizing radiation. This is mainly due to the innovations and application of techniques for media, communication and other mobile applications. Though non-ionizing radiation is generally not considered as hazardous as the ionizing radiation, Standing Committee on Epidemiology of the International Commission for Non-Ionizing Radiation Protection undertook a comprehensive review of epidemiologic studies to assess the effect of radiofrequency fields on human health. The review included a large number of occupational studies over several decades, particularly on cancer, cardiovascular disease, adverse reproductive outcome and cataract, studies of residential exposure on leukaemia and studies of mobile telephone users on brain tumours. The review concluded that there is no consistent or convincing evidence of a causal relation between radio frequency exposure and any adverse health effect. However, it revealed some indications of an increased risk of glioma for those who reported the highest $10 \%$ of cumulative hours of cell phone use, although there was no consistent trend of increasing risk with greater duration of use. Based largely on these data, the International Agency for Research on Cancer (IARC) has classified radiofrequency electromagnetic fields possibly as carcinogenic to humans (Group 2B), a category used when a causal association is considered credible, but when chance, bias or confounding cannot be ruled out with reasonable confidence. The review also noted the limitations related to flaws in studies under review, including the quality of assessment of radio frequency 
exposure and absence of data on consequences of childhood exposure. Despite this status quo, we need to take precautions before it would be too late. It should be kept in mind that it took almost a century to conclude on the adverse health effects of smoking. Even after gathering enough evidence, still the humankind is struggling to get rid of this habit. As such, until data is available, it is rational to limit or stop the unnecessary and excessive exposure of children to radiation and strictly adhere to the safety measures introduced for the protection of occupational exposure.

\section{Community noise}

Community noise which is also called 'environmental noise', 'residential noise' or 'domestic noise' is defined as noise emitted from all sources except noise at the industrial workplace. Sources include noise from automobiles, construction work, loudspeakers, recreational activities, fireworks, to name a few. The adverse health effects of noise include auditory disorders such as hearing impairment, tinnitus, ear ache, noise-induced hearing loss and non-auditory manifestations such as headache, psychological disturbances, irritability, inability to concentrate, disturbance in sleep and rest, and interference with speech communication. Measures proposed by the WHO for managing noise include monitoring of human exposure to noise, applying control measures on a priority basis to mitigate noise emissions, controlling noise during specific times of the day; taking noise into consideration during urban planning and transport planning; introducing surveillance on noise related adverse health effects; and developing policies to address noise related issues. Trying to control all types of noise giving equal weight is a sensitive issue. However, there is a vast area for improvement other than those sensitive areas.

\section{Occupational risks}

Occupational risks originate from the environment. In addition to the physical environment of the workplace, functional aspects such as operational, social, administrative environments also matter when determining the health of workers. There is much room for improvement and need more attention towards poorly organized and informal occupational setups.

\section{Agricultural practices}

Today, humans cannot exist without farming of both plant crops and animals. Environmental adverse effects of farming are evident throughout the evolution of mankind. Deforestation and desertification are probably the oldest such effects. According to One Green Planet (2017), some 36 football fields of forests are hacked, burned and destroyed every minute. With each forest clearing, we lose about 135 species of animals, plants, and insects a day due to deforestation (11). The main causes of deforestation are due to agricultural practices. Modern farming has contributed to numerous other adverse effects directly affecting the human health. Pollutants from farming include pesticides, chemical fertilizers sediments, nutrients, pathogens, metals and salts, of which pesticides pose the greatest risk.

A pesticide is any substance intended to control, destroy, repel or attract a pest. The target pest could be any living organism that causes damage, economic loss, transmits or produces disease. Pesticides Act, No. 33 of 1980 of Sri Lanka gives its own definition of a pesticide as any substance intended for use or used for controlling a pest and shall include active ingredients, adjuvant and pesticide formulations.

Pesticides are unique among toxic substances polluting the environment. Most environmental toxins are unwanted by-products of another process. Pesticides are chemicals designed to be toxic to a target pests and purposely introduced into the environment to manage pests. Pesticides can enter the body through inhalation of aerosols, dust and vapour that contain pesticides through oral exposure by consuming food/water and through skin exposure by direct contact. Pesticides can seep into soil and groundwater which can end up in drinking water while pesticide spray can drift and pollute the air. The effects of pesticides on human health depend on the toxicity of the chemical and the length and magnitude of exposure. Agricultural workers and their families experience the greatest exposure to agricultural pesticides through direct contact. In broad terms, exposure effects of pesticides can range from mild skin irritation to birth defects, tumour, genetic changes, blood and nerve disorders, endocrine disruption, coma or death. 
Early initiatives of Pesticide Regulation in Sri Lanka took place in 1960s. However, Control of Pesticides Act No. 33 of 1980 became effective in September 1980. This Act is enforced by Registrar of Pesticides of the Ministry of Agriculture under the guidance of the Pesticide Technical Advisory Committee. Regulation of pesticides in Sri Lanka is considered one of the major investments contributing to make the nation healthy. Areas with greatest impact include: banning/ restriction of highly hazardous pesticides; restriction of unnecessary pesticides; restrictions imposed on marketing and advertising of pesticides; mandatory labelling/consumer information and education; and the ability to address specific public health issues on a case by case basis such as paraquot and glyphosate.

Misuse/abuse of chemicals in agriculture is another important agricultural practice that can affect both the user (excessive use, use beyond intended purposes, use of excessive concentrations, use without personal protection and use for self-harming) and the public (general environmental pollution - air, water, soil and food, late pre harvest application, post-harvest application, inappropriate application, improper disposal and unsafe storage). Impact of the misuse/ abuse of chemicals in agriculture may surface as environmental pollution, food safety issues, medical emergencies and chronic illnesses, in most occasions of unknown origin. Improving awareness, strengthening of supervision and enforcement, and provision of incentives for good practices could be identified for future investment aiming at improving environment health related to agricultural practices.

\section{Built environment}

As humans spend a considerable proportion of their life indoors, conditions of housing are linked to their health. Evidence indicates that the home, despite highly developed technologies, materials and construction styles remains a major cause for ill health through exposure to many factors, including but not limited to home injuries, indoor air quality issues, chemicals (cleaning products, asbestos and heavy metals), over-crowding, mould and dampness, noise, radon, pests and infestations, poor access to water and sanitation, proximity to pollution sources or flooding and inadequate protection from extreme weather.

Measures to ensure houses conducive to improved health have been recognized way back in 1915 when the Housing and Town Improvement Ordinance was enacted. Regulations published under this ordinance clearly spell out the conditions and pre-requisites for healthy housing. Going beyond making a house healthy, incorporation of housing into the environment and facilitating the sustainability of both environment and human life are important aspects.

The process of incorporation of a large number of human habitats into the environment together with other components essential for human life in an organized manner is called urban planning. Planned urbanization aims at positive change in the multidimensional society. In contrast, unplanned urbanization and settlements leave adverse effects on health, sanitation, security and housing as well create social issues such as crime and violence. At an extreme level, it is associated with over-population; haphazard housing services; urban poverty; child labour; poor access to education; mismanagement of waste, air, water, sound and soil pollutions; and drug abuse, to name a few. Walkability is a measure of how friendly an area is for walking. It is an important concept in sustainable urban design with health, environmental and economic benefits. Factors influencing walkability include the presence and quality of footpaths, sidewalks or other pedestrian rights-of-way, traffic and road conditions, land use patterns, building accessibility and safety. Neighbourhoods with more walkability had lower rates of obesity as well as increased physical activity among its residents. In Sri Lanka, owing to high humidity, walking outdoors is not a pleasant affair. Anyone walking outdoors is likely to be battered either by the sun or by the rain. In response, during colonial times, arcades were built in most buildings facing the roads in Colombo as well as in other major cities. After the independence, it seems that we have abandoned this practice and have preferred to use a three wheeled taxi even for short distances. Just like the walkability, bikeability is another measure of healthy urban planning. We have already embraced the motor bikeability in an irrevocable manner, thus it is prudent that we promote the use of bicycles in areas where it is practised, before they too embrace the motorbike.

\section{Climate change}

Climate change refers to changes in the mean and/ or variability of properties in the climate, which persist for an extended period typically decades or longer (12). Effects of climate change and their impact on 
human health are well documented. Concerted efforts for climate change mitigation and adaptation should be a priority area. Those involved in this process should be much-admired and be optimistic as we have had past evidence of success in related issues.

Acknowledgments: All the sources of information on environmental health including text books, websites and other documents

\section{References}

1. Bassett WH (Ed). Clay's Handbook of Environmental Health. London: Spon Press, 2004.

2. Frumkin $\mathrm{H}(\mathrm{Ed})$. Environmental Health - From Global to Local. San Francisco: John Wiley \& Sons, 2004.

3. National Environmental Health Association. Definitions of environmental health. Denver, 2017. Available from: https://www.neha.org/about-neha/ definitions-environmental-health.

4. WHO. Constitution of the World Health Organization. Basic documents (45th edition), Supplement. Geneva: World Health Organisation, 2006.

5. Numbeo. Database on air pollution 2017. Available from: https://www.numbeo.com/pollution/ rankings_current.jsp.

6. Nandasena YL, Wickremasinghe AR, Sathiakumar N. Air pollution and health in Sri Lanka: a review of epidemiologic studies. BMC Public Health 2010; 10: 300.

7. Sri Lankan Scientist. Colombo air too is polluted says WHO, 2016.

Available from: http://scientist.lk/2016/10/28/ colombo-air-too-is-polluted-says-who/.

8. Department of Motor Traffic. Statistics 2017. Colombo: Ministry of Transport and Civil Aviation, 2017.

Available from: http://www.transport.gov.lk/web/ index.php/en/statistics/department-of-motortraffic.html.

9. DCS. Demographic and Health Survey - 2016, Sri Lanka. Colombo: Department of Census \& Statistics, 2016.

10. WHO. Chemical hazards. Geneva: World Health Organisation, 2017.

Available from: http://www.who.int/ceh/risks/ cehchemicals/en/.

11. One Green Planet. Five big causes of deforestation and how you can stop it, 2017.

Available from: http://www.onegreenplanet.org/ animalsandnature/5-big-causes-of-deforestation-andhow-you-can-stop-it/.

12. IPCC. Inter-governmental Panel on Climate Change Fourth Assessment Report: Climate Change 2007. Geneva: WHO, 2007.

Available from: https://www.ipcc.ch/publications and_data/ar4/wg1/en/ch9s9-1.html. 